\title{
Transvaginal three-dimensional ultrasound for preoperative assessment of myometrial invasion in patients with endometrial cancer: a systematic review and meta-analysis
}

\author{
Tatiana Costas ${ }^{1}$, Rocío Belda ${ }^{2}$, Juan Luis Alcázar ${ }^{3}$
}

${ }^{1}$ Department of Obstetrics and Gynecology, University Hospital Salamanca, Salamanca, ${ }^{2}$ Department of Obstetrics and Gynecology, General University Hospital, Valencia, ${ }^{3}$ Department of Obstetrics and Gynecology, University Hospital of Navarre, School of Medicine, University of Navarra, Pamplona, Spain

\begin{abstract}
Aim: The aim of this meta-analysis is to evaluate the diagnostic accuracy of three-dimensional transvaginal ultrasound subjective assessment (3D-TVS) in the preoperative detection of deep myometrial invasion (MI) in patients with endometrial cancer, using definitive frozen section diagnosis after surgery as the reference standard. Material and methods: A search for studies evaluating the role of 3D-TVS for assessing myometrial invasion in endometrial cancer from January 1990 to November 2020 was performed in PubMed/MEDLINE and Web of Science. The Quality Assessment of Diagnostic Accuracy Studies 2 evaluated the quality of the studies (QUADAS-2). All analyses were performed using MIDAS and METANDI commands. Results: Nine studies comprising 581 women were included. The mean prevalence of deep MI was 39.8\%. QUADAS assessment showed that most studies had a high risk for the patient selection domain. Overall, the pooled estimated sensitivity, specificity, positive likelihood and negative likelihood ratio of 3D-TVS for detecting deep MI were 84\% (95\% CI, 73-90\%), $82 \%$ (95\% CI, 75-88\%), 5 (95\% CI, 3.1-7.1) and 0.20 95\% CI, 0.11-0.35). respectively. Conclusions: 3D-TVS has an acceptable diagnostic performance for detecting $\mathrm{MI}$ in women with endometrial cancer.

Keywords: endometrial cancer; meta-analysis; myometrial invasion; systematic review; three-dimensional transvaginal ultrasound
\end{abstract}

\section{Introduction}

Cancer of the corpus uteri, mainly endometrial cancer (EC), is the sixth most frequent form of cancer in women worldwide, being the most common cause of gynaecologic malignancy in developed countries, with an incidence of 12.9/100.000 women and a mortality rate of 2.4/100.000 women. The most important prognosis

Received 25.11.2020 Accepted 31.01.2021

Med Ultrason

2022, Vol. 24, No 1, 77-84

Corresponding author: Juan Luis Alcazar, MD, $\mathrm{PhD}$ ORCID ID: 0000-0002-9700-0853

Department of Obstetrics and Gynecology.

Clínica Universidad de Navarra.

36 Avenida Pío XII, 3110 Pamplona Spain

Phone: +34-948-296234

Fax: +34-948296500

E-mail: jlalcazar@unav.es features for EC are FIGO stage (International Federation of Gynaecology and Obstetrics), myometrial infiltration (MI), histological type and differentiation grade. Among these, $\mathrm{MI} \geq 50 \%$ is associated with both pelvic lymph node involvement and extension into the parametrium [1]. Even in low-grade endometroid tumours, lymph node metastasis risk increases from $4 \%$ to $15 \%$ if the tumour invades more than $50 \%$ of the myometrium [2]. These women are at a higher risk of recurrence and might benefit from an extended surgical staging with systematic pelvic and para-aortic lymphadenectomy in order to tailor adjuvant therapy. It is important to avoid overtreatment, as most of these women are elderly with comorbidities. Lymphadenectomy shows no survival benefit in lowrisk endometrial cancer patients and, in fact, results in increased complications and higher morbidity [3-7]. For this reason, many authors advocate intraoperative gross or frozen section evaluation of the myometrial invasion 
in clinical stage I endometrial carcinoma to aid the decision of whether lymphadenectomy should be performed or not. Frozen section has shown to be highly accurate (94\%) for determining myometrial invasion [8]. However, it may be time consuming and it is not performed in all hospitals. Therefore, a method that could reliably assess myometrial invasion preoperatively would be helpful to provide individual tailoring of the surgical approach [9].

There is no consensus about the optimal imaging technique for evaluation of myometrial and cervical invasion. Two-dimensional transvaginal ultrasound (2D-TVS) and magnetic resonance imaging (MRI) have shown accuracies of $69-74 \%$ and $66-90 \%$ respectively [10-13]. Threedimensional transvaginal ultrasonography (3D-TVS) has several advantages when evaluating myometrial infiltration [14]. However, although several studies have shown the utility of this technique in myometrial evaluation of $\mathrm{EC}$, the routine implementation in clinical practice has not been stablished so far. Theoretically, from an efficient point of view, the assessment of pre-surgical staging with 3D-TVS reveals a notorious benefit in terms of economic approach as compared to MRI. Since the advent of 3DTVS, several studies have been published aiming at evaluating the role of this technique for detecting the depth of myometrial infiltration in endometrial cancer.

On the other hand, more hospitals, especially in developed countries, tend to implement 3D-TVS in their daily practices, revealing an increasing need of training and investigation of the actual performance of this technique. To the best of our knowledge, not a single metaanalysis analysed the diagnostic performance of 3D-TVS for detecting myometrial invasion in women with EC.

Thus, the purpose of this systematic review and meta-analysis is to evaluate the diagnostic accuracy of 3D-TVS in the preoperative detection of deep myometrial invasion in patients with endometrial cancer, using definitive frozen section diagnosis after surgery as the reference standard.

\section{Material and methods}

\section{Protocol and registration}

This systematic review and meta-analysis has been made according to the PRISMA Statement [15]. All methods for inclusion and exclusion criteria, data extraction and quality assessment were specified in advance. The protocol was not registered.

\section{Data sources and searches}

Two electronic databases, PubMed/Medline and Web of Science were screened in November 2020 by three of the authors (TC, RB and JLA) to identify eligible studies. "Endometrial cancer", "ultrasound" and "three-di- mensional" were used as a search terms. No other methodological filters in the database were included to avoid possible omission of relevant studies, according to the recommendation of Leeflang et al [16].

\section{Study selection and data collection}

Two authors (TC and RB) screened the titles identified by the searches to exclude irrelevant articles, not strictly related to the topic. Abstracts of these articles were revised and some of these articles were excluded due to no relevant content (not relevant topic) or nonEnglish languages. Full text publications were independently analysed by two authors (TC and RB) who read and collected data of all the publications.

Inclusion criteria were: 1) Use of 3D-TVS as index test to assessment myometrial invasion preoperatively with subjective impression estimation of myometrial invasion (less than $50 \%$ of myometrium or more) by the investigator/s; 2) Reference standard was surgical pathological data; 3 ) Presence of results sufficient to construct the $2 \times 2$ table of diagnostic performance as minimum data requirement. To avoid inclusion of duplicate cohorts from at least two pair of studies reported by the same authors, the study period of each study was examined. If dates overlapped, the latest study published or the study that could provide us a $2 \times 2$ table was chosen. Disagreements arising during the process of study selection and data collection were resolved by consensus among three authors (JLA, TC and RB)

The PICOS (Patients, Intervention, Comparator, Outcome, Study design) criteria used for inclusion and exclusion of studies are shown in Table I. Diagnostic accuracy and additional useful information on patients and procedures were retrieved from a selected primary study written independently by the same authors (JLA, $\mathrm{TC}$ and $\mathrm{RB}$ ).

\section{Risk of bias in individual studies}

Quality assessment was conducted using the tool provided by QUADAS (Quality Assessment of Diagnostic Accuracy Studies -2). The QUADAS-2 format includes four domains: 1) patient selection, 2) index test, 3) reference standard, 4) flow and timing. For each domain, the risk of bias and concerns regarding applicability was analysed and rated as low, high and unclear risk. The quality assessment was used to provide an evaluation of the overall quality of the studies and to investigate potential sources of heterogeneity.

Three authors (JLA, TC and RB) evaluated the methodological quality independently. Disagreements were solved by discussion among these authors. The assessment of quality was based on whether the study described the study's design as well as inclusion and exclusion criteria for the patient selection domain. The evaluation of 
quality for the index test domain was based on whether the study reported on how the index test (3D-TVUS) was performed and interpreted. The evaluation of quality for the reference standard domain examined the reference standard used in each study and if sonographers and pathologists were blind or not to the index test. For the flow-and-timing domain's evaluation, a description of the time elapsed from the index test assessment to the reference standard result was evaluated.

\section{Statistical analysis}

We extracted or derived information on diagnostic performance of 3D-TVS. Although other techniques were used in the studies (such as RMI or 2D-TVS), only the data from 3D-TVS evaluations were recollected. Primary outcome was pooled sensitivity, specificity, positive predictive value, negative predictive value and for instance, true positive, true negative, false positive and false negative values were obtained. Post-test probabilities were calculated and plotted on Fagan nomograms.

Heterogeneity of all studies was graphically explored, drawing forest plots of sensitivity and specificity. We then formally assessed the presence of heterogeneity for sensitivity and specificity using Cochran's Q test and the $\mathrm{I}^{2}$ Index. A test for heterogeneity examines the null hypothesis that all studies are evaluating the same effect (Higgins et al [17]).

Cochran's Q statistic is computed by summing the squared deviations of each study's estimate from the overall meta-analytic estimate, weighting each study's contribution in the same manner as in the meta-analysis. A p-value $<0.1$ indicates heterogeneity. The $\mathrm{I}^{2}$ index describes the percentage of total variation across studies that is due to heterogeneity rather than chance. According to Higgins et al values of $25 \%, 50 \%$, and $75 \%$ would be considered to indicate low, moderate and high heterogeneity, respectively [17].

Summary receiver-operating characteristics (sROC) curves for each approach were plotted to illustrate the relationship between sensitivity and specificity.

All analyses were performed using Meta- analytical integration of Diagnostic Accuracy Studies (MIDAS) and METANDI commands in STATA version 12 for Windows (Stata Corporation, College Station, TX, USA). pvalue $<0.05$ was considered statistically significant.

\section{Results}

\section{Search results}

The electronic search provided 108 citations. A flowchart summarizing literature identification and selection is given in Figure 1. Eighty-three of them were excluded due to no relevant topic (i.e. 3D MRI) or being review

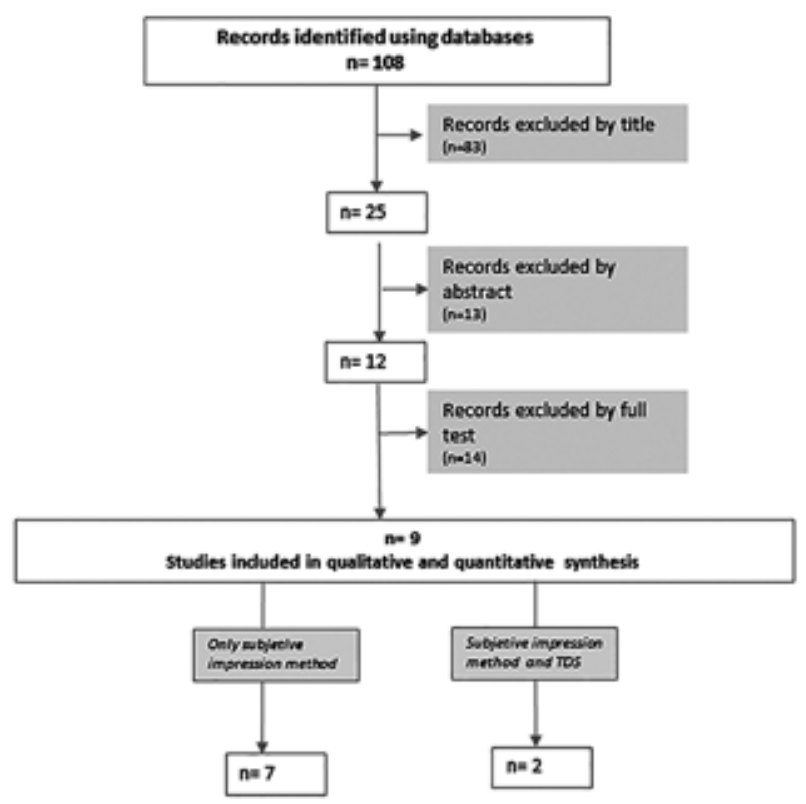

Fig 1. Flow chart showing studies selection process.

papers, 12 were excluded after reading abstract (not relevant to the review) and one due to other language than English (Chinese $\mathrm{n}=1$ ). The full text of the remaining twelve articles were examined. One of them [18] was excluded due to the impossibility of obtain $2 \times 2$ tables. Alcázar et al [19] and Mascilini et al [20] analysed myometrial invasion with TDS and tumour/uterine volume $3 \mathrm{D}$ ratio without subjective impression as a method. For that reason, they were also discarded.

Nine studies were finally taken into account [9,14,18,21-26] (Table I). All studies analysed myometrial invasion with "subjective impression method". No additional relevant studies were found from references cited in the papers included in the review. A flowchart summarizing literature identification and selection is given in Figure 1.

\section{Characteristics of included studies}

The nine studies $[9,14,18,21-26]$ published between 2009 and 2019, reported data from 581 patients, 231 women having myometrial invasion $\geq 50 \%$ in the definitive pathological samples. This was considered as the prevalence and, therefore, pre-test probability.

The mean patient age was reported in 8 out of the 9 studies, in Trujillo et al no reference to this item being made [22]. Patients' mean age was 61.4 years, ponderated by the number of patients in each study. The prevalence of $\geq 50 \%$ myometrial invasion was $39.8 \%$. Hormonal status differentiating between pre- and postmenopausal women was given in 3 out of 9 studies [14,21,26]. The differentiation between histological grades was referred in all papers except for Green et al [23] and Jantarasaen- 
Tatiana Costas et al Transvaginal 3D US for preoperative assessment of myometrial invasion in patients with endometrial cancer

Table I. Characteristics of the studies included in the current meta-analysis according to PICO criteria

\begin{tabular}{|c|c|c|c|c|c|c|c|c|c|}
\hline $\begin{array}{l}\text { Author, } \\
\text { year }\end{array}$ & $\begin{array}{l}\text { Study's } \\
\text { Design }\end{array}$ & Setting & $\begin{array}{l}\text { Consecutive } \\
\text { recruitment }\end{array}$ & $\mathbf{N}$ & $\begin{array}{l}\text { Cases with } \\
\mathrm{MI} \geq \mathbf{5 0 \%}\end{array}$ & $\begin{array}{l}\text { Index } \\
\text { test }\end{array}$ & $\begin{array}{l}\text { Method of } \\
\text { assessment }\end{array}$ & Observers & $\begin{array}{l}\text { Reference } \\
\text { test }\end{array}$ \\
\hline $\begin{array}{l}\text { Alcázar, } \\
2009 \text { [9] }\end{array}$ & Prospective & $\begin{array}{l}\text { Multi- } \\
\text { center }\end{array}$ & Yes & 113 & 27 & 3D-TVS & Subjective & Two & $\begin{array}{l}\text { Definitive } \\
\text { histology }\end{array}$ \\
\hline $\begin{array}{l}\text { Saarelainen, } \\
2012 \text { [18] }\end{array}$ & Prospective & $\begin{array}{l}\text { Single } \\
\text { center }\end{array}$ & Yes & 20 & 12 & 3D-TVS & Subjective & Single & $\begin{array}{l}\text { Definitive } \\
\text { histology }\end{array}$ \\
\hline $\begin{array}{l}\text { Jantarasaengaram, } \\
2014 \text { [14] }\end{array}$ & Prospective & $\begin{array}{l}\text { Single } \\
\text { center }\end{array}$ & Yes & 40 & 11 & 3D-TVS & Subjective & Single & $\begin{array}{l}\text { Definitive } \\
\text { histology }\end{array}$ \\
\hline $\begin{array}{l}\text { Christensen, } \\
2015 \text { [24] }\end{array}$ & Retrospective & $\begin{array}{l}\text { Single } \\
\text { center }\end{array}$ & Unclear & 110 & 47 & 3D-TVS & Subjective & Two & $\begin{array}{l}\text { Definitive } \\
\text { histology }\end{array}$ \\
\hline $\begin{array}{l}\text { Rodríguez-Trujillo, } \\
2016 \text { [22] }\end{array}$ & Retrospective & $\begin{array}{l}\text { Single } \\
\text { center }\end{array}$ & Yes & 98 & 39 & 3D-TVS & Subjective & Single & $\begin{array}{l}\text { Definitive } \\
\text { histology }\end{array}$ \\
\hline $\begin{array}{l}\text { Ergeneglu, } \\
2016[21]\end{array}$ & Prospective & $\begin{array}{l}\text { Single } \\
\text { center }\end{array}$ & Unclear & 45 & 9 & 3D-TVS & Subjective & Single & $\begin{array}{l}\text { Definitive } \\
\text { histology }\end{array}$ \\
\hline $\begin{array}{l}\text { Green, } \\
2018 \text { [23] }\end{array}$ & Retrospective & $\begin{array}{l}\text { Single } \\
\text { center* }\end{array}$ & Yes & 58 & 31 & 3D-TVS & Subjective & Multiple & $\begin{array}{l}\text { Definitive } \\
\text { histology }\end{array}$ \\
\hline $\begin{array}{l}\text { Yildrim, } \\
2018 \text { [26] }\end{array}$ & Prospective & $\begin{array}{l}\text { Single } \\
\text { center }\end{array}$ & Unclear & 40 & 45 & 3D-TVS & Subjective & Multiple & $\begin{array}{l}\text { Definitive } \\
\text { histology }\end{array}$ \\
\hline $\begin{array}{l}\text { Yang, } \\
2019 \text { [25] }\end{array}$ & Retrospective & $\begin{array}{l}\text { Single } \\
\text { center }\end{array}$ & Unclear & 78 & 22 & 3D-TVS & Subjective & Two & $\begin{array}{l}\text { Definitive } \\
\text { histology }\end{array}$ \\
\hline
\end{tabular}

* In the case of Green et al, women included as subjects of the study came from the same center. However, the examiners were spread all over Europe, N - number of patients, MI - myometrial invasion

garam et al [14], This last author excludes all G3 cases as being considered high-risk profile. All studies described data regarding tumour histological type (endometroid and non-endometroid) except for Christensen et al [24].

As mentioned before, in all studies selected for quantitative analysis, method to estimate myometrial invasion was the subjective impression on 3D-TVS by examiner/s.

Most of the publications studied in this meta-analysis make a comparison between subjective impression with 3D-TVS and MRI [18,22,24-26]. Two papers also compared subjective impression with 3D-TVS and objective methods with 3D-TVS $[9,21]$. Another paper compares 2D-TVS and 3D-TVS [23]. Only one publication uses the subjective impression of 3D-TVS as the only method assessed [14]. Pathological evaluation of the removed uterus was considered as a reference standard in all papers.

\section{Methodological quality of included studies}

A graphical display of the risk evaluation of bias and concerns regarding applicability of the selected studies, according to predefined criteria, is shown in figure 2 .

Regarding risk of bias and the domain patient selection, all of them explain specifically patterns of inclusion. Three studies do not include advanced stage patients $[14,22,24]$. Christensen et al [24] included endometrial hyperplasia with atypia in preoperative histology into the group of patients studied. This last case can increase the risk of overestimating the accuracy of 3D-TVS for the estimation of $<50 \%$ of MI. In contrast, the exclusion of advanced stage cases was not considered a risk of bias, in spite that this technique is relevant especially for early stages since true tumour stage can only be determinated after surgery. One study excluded patients with leiomiomas greater than $3 \mathrm{~cm}$ and submucous myomas [21]. This study was considered as a high risk for bias in patient selection domain since selecting exclusively ideal patients for the validation of the 3D-TVS, can suppose a bias in the validity of the test. Two studies $[9,21]$ excluded patients whose videos are incomplete and one study excludes patients with suboptimal image resolution (classified by score 3 of 4 of quality) [14]. Incomplete videos is understandably criteria for exclusion, but if only optimal image resolution is selected, the scenario left is made up of exclusively ideal situations and this can lead to an overestimation of the accuracy of the test.

Regarding the study design, prospective design with US prior to surgery is carried out in 5 of the 9 studies $[9,14,18,21,26]$. The rest of papers describe retrospective methodology. Christensen et al [24] evaluated the volume of the uterus 6 months after surgery, the US examiners being blinded to the pathological result. In 2 of the retrospective studies the examiner was blinded to the pathology $[23,24]$ and in 2 studies no explanation was provided $[22,25]$.

Concerning the domain index test, all studies describe clearly the index test as well as how it was performed and interpreted. However, Christensen et al [24], describing a 4-step subjective methodology (1- initial subjective evaluation, 2- TUI function, 3- render function and 

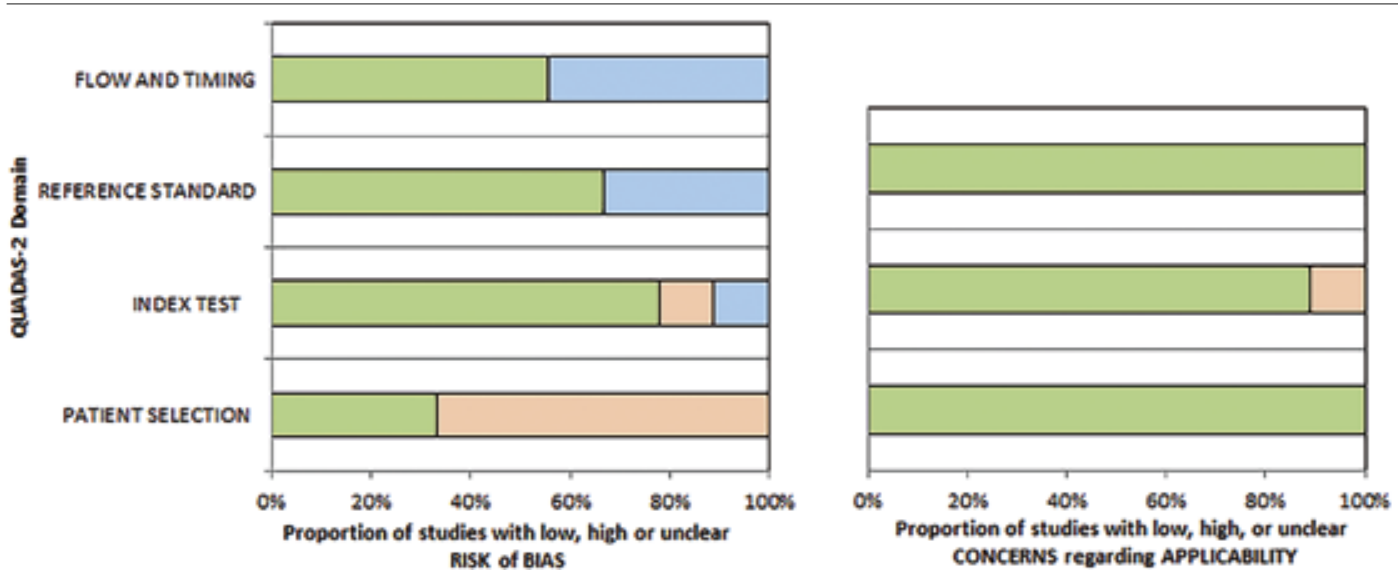

Fig 2. Histogram plot quality assessment (risk of bias and concerns about applicability) for all studies included in the meta-analysis. QUADAS indicates Quality Assessment of Diagnosis Accuracy Studies.

4- final evaluation with all gathered information), did not clearly define the importance given to each of these sub methods, leaving a riddle to understand the real criteria used in this study. All studies adopted the same pre-specified threshold to define deep MI ( $\geq 50 \%$ of myometrial thickness in any of the three spatial orthogonal planes). Four out of nine studies disposed $\geq 2$ TVS examiners, and the remainder had one expert examiner for all patients $[9,23,25,26]$. From the group which included $\geq 2$ examiners, Christensen et al [24] disposed of examiners with limited experience in 3D TVS and Alcazar et al [9] mixed both experts and beginners. The rest of them were experts. In two of the retrospective cases, as mentioned before, the blind condition of examiners to histological final results is not clearly defined, considering, in consequence, an unclear risk of bias 22.25].

Concerning the domain reference standard, all studies stated that histology was analysed after uterus removal, but most of them did not describe how this was done (frozen section method was only mentioned in 2 of the studies $[20,25])$. Three papers do not mention if the pathologist was blind to the 3D-TVS conclusions, leaving the risk of bias in these cases unclear $[14,21,26]$.

Time and flow were not specified in four of the studies included [21-23,25].

Concerning regarding applicability, all studies were considered as low concern for patient selection domain. The incidence of EC is high; however, advanced stages of this neoplasia are not usually susceptible for 3D-TVS as they already implicate a surgical attitude; EC is usually diagnosed in early stages, motivating the patients' selection.

Index test has not been found to implicate a high concern of applicability in any of the studies of this metaanalysis, except for Christensen et al [24] as a consequence of the above mentioned 4-step method.
Reference standard concern of applicability was not found to be high in any case, as histological definitive sample is usually the reference test in all gynaecology clinics .

Diagnostic performance of 3D-TVS for detection of deep myometrial invasion

We analysed the overall sensitivity and specificity of 3D-TVS in all studies to determine pulled sensitivity, specificity, LR+ and LR- of subjective impression in 3DTVS in detecting deep MI. Results were 84\% (95\% CI, 73-90\%), 82\% (95\% CI, 75-88\%), 5.0 (95\% CI, 3.1-7.1) and $0.295 \% \mathrm{CI}, 0.1-0.3)$ respectively. Diagnostic odds ratio (DOR) was 23.0 (95\% CI, 9.0-59.0). sROC curve is shown in figure 3 . Area under the curve was 0.89 (95\% CI: 0.86-0.92)

Heterogeneity was moderate for sensitivity $\left(\mathrm{I}^{2}, 65.5 \%\right.$ (95\% CI 41.4-90.0\%)) and for specificity $\left(\mathrm{I}^{2}, 65.1 \%\right.$ (95\% CI 40.3-89.9\%)). Data are shown in figure 4.

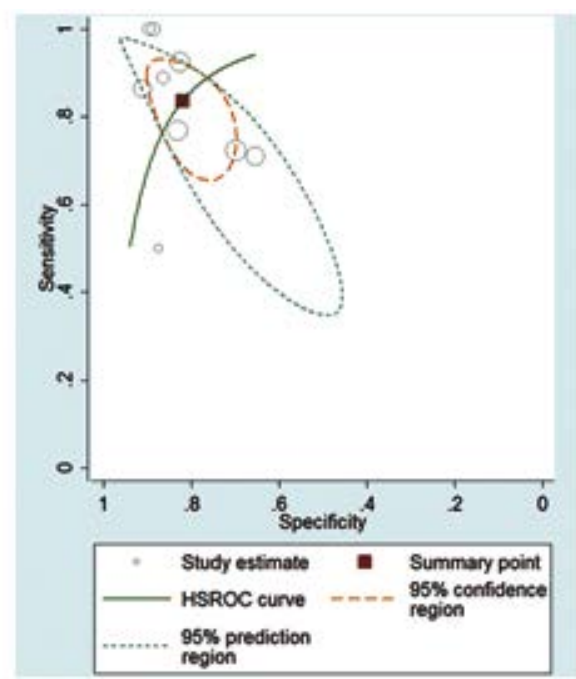

Fig 3. Summary receiver operating characteristic curve for 3DTVS. 
Fagan nomograms show that a positive test significantly increased the pretest probability of MI $50 \%$ while a negative significantly decreased the pre-test probability of MI $\geq 50 \%$ (fig 5 ). We did not observe publication bias (fig 6).

\section{Discussion}

EC is considered a neoplasia with good prognosis in terms of survival when the diagnosis is made at an early stage. The differences between the survival rates observed in stage 1 compared to those seen in stage 3 are overwhelming: according to the American Cancer Society the survival rate in early stages reaches $95 \%$ but it decreases to $17 \%$ in distant spreading [27]. Thus, the importance to find tests that lead to a better staging has become a challenge for the gynecological community.

As there is a really improvement of the rates in early cancer detection, new needs emerge from the elevated number of patients waiting for attending. In consequence, the efficiency of tests used for pre-surgical staging started to be an important object of investigation. In this context, MRI and 2D-TVS are currently considered the imaging techniques of choice for estimating MI before surgery [28]. Alcázar et al [9] in 2009 were the first authors that studied the performance of 3D-TVS. Since then, several studies using 3D-TVS for detecting MI have been reported.

We found that the overall diagnostic performance of 3D-TVS in detecting deep MI in women with EC have A pooled sensitivity of $84 \%$ and pooled specificity of $81 \%$, subjective method being the reference measurement technique.

To the best of our knowledge, this is the first metaanalysis that evaluates subjective impression in 3D-TVS as the method of estimation of MI in women with EC reported to date.

The principal limitation in our meta-analysis is the low number of papers reported. The total sum of patients studied of 581. In this group of studies, moderate heterogeneity has been also found. Besides, the small sample the data reported should be interpreted carefully. In addition, there has not been a proper analysis of the objective methods used by some authors. However, we do consider that this could have increased the heterogeneity and we decided to exclude them. Due to the reduced number of papers published that describe objective methods, subanalysis was non-viable.

Regarding generalizability, Alcazar et al published a meta-analysis in which 2D-TVS showed 78\% (95\% CI, $72-83)$ sensibility and $81 \%(95 \% \mathrm{CI}, 71-87)$ specificity [29]. In this same study, objective methodology with

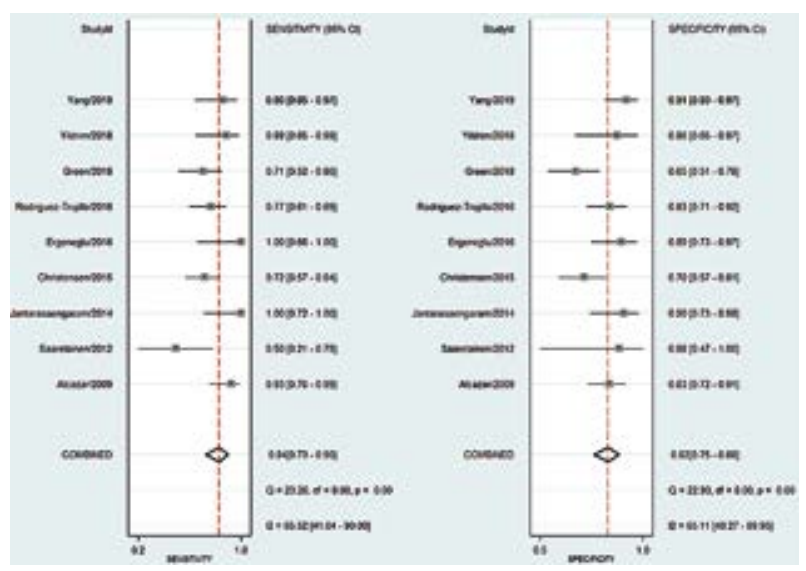

Fig 4. Forest plot of studies evaluated for subjective impression in 3D-TVS for the assessment of myometrial invasion. Summary sensitivity and specificity as well as heterogeneity statistics (Cochran's Q and $\mathrm{I}^{2}$ ) are shown.

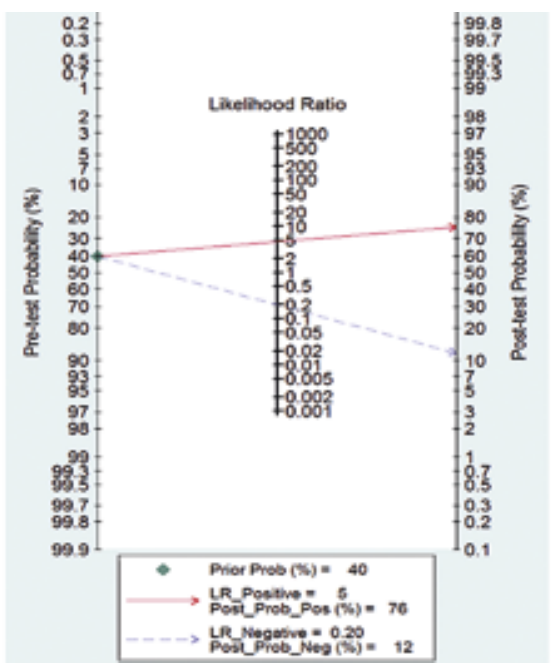

Fig 5. Fagan normogram for detecting miometrial invasion with subjective impression in 3D-TVS.

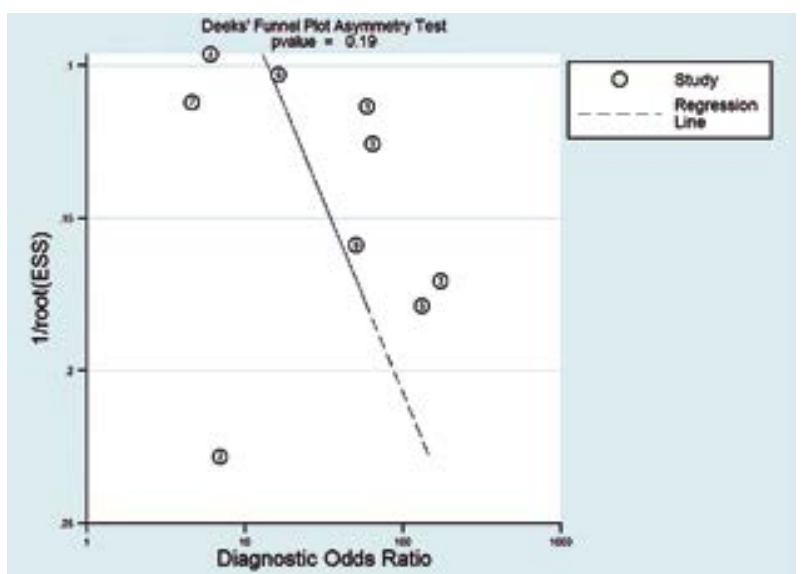

Fig 6. Deeks funnel plot for assessing publication bias $(p=0.19)$ ESS indicates effective sample size. 
Karlson and Gordon's methods for the estimation of myometrial infiltration showed a sensibility of $84-85 \%$ and $82-80 \%$ specificity, respectively. In 2017, Alcázar compared 2D-TVS and MRI by meta-analysis. In this case, with a sample of 560 patients they reached a sensitivity of $75 \%$ and specificity of $86 \%$ for 2D-TVS [28].

Subjective 3D-TVS has, then, slightly superior results than those obtained by subjective methods in 2DTVS and very similar results from objective methods of 2D-TVS.

MRI has been considered a good imaging test for evaluating MI. Recent studies demonstrated a pooled sensitivity ranging from $81 \%$ to $90 \%$ and pooled specificities ranging from $82 \%$ to $89 \%$. No differences were found in these studies between contrast enhanced MRI and diffusion weighted MRI [28,30-32].

When comparing data from several meta-analyses about MRI with the data we have obtained in our meta-analysis regarding 3D-TVS, we observe that, roughly, diagnostic performance seems to be similar [28,30-32].

Objective methods in 3D-TVS have been studied. Alcazar describes TDS method as an objective method [9]. In this case, sensibility reaches $81.7 \%$ and specificity $41.5 \%$. Ergenoglu validates this method demonstrating sensibility $89 \%$ and specificity $61 \%$ [21]. Another objective method described described by Mascilini et al [20] is tumor volume/uterine volume ratio. With this method, sensitivity reported in some studies was $90.5 \%$ and $60 \%$, respectively, whereas, specificity was $28.5 \%$ and $85 \%$, respectively $[19,20]$.

However, we did not find a representative number of prospective studies dedicated exclusively to the comparison of 2D-TVS and 3D-TVS methods for MI assessment in EC. Also, lack of information has been identified regarding the objective methods used for 3D-TVS assessment. We think it is important to dedicate the investigation to the objective methods used in 3D-TVS evaluation for improving the quality of comparison with subjective 3D-TVS methods.

In conclusion, subjective impression in 3D-TVS seems to be an appropriate method for the estimation of MI of EC in early stages. However, as we have observed a high risk of patient selection bias, it is necessary to increase the number of prospective well-designed studies in this area.

\section{Conflict of interest: none}

\section{References}

1. Jemal A, Bray F, Center MM, Ferlay J, Ward E, Forman D. Global cancer statistics. CA Cancer J Clin 2011;61:69-90.
2. AlHilli MM, Podratz KC, Dowdy SC, et al. Risk-scoring system for the individualized prediction of lymphatic dissemination in patients with endometroid endometrial cancer. Gynecol Oncol 2013;131:103-108.

3. Morrow CP, Bundy BN, Kurman RJ, et al. Relationship between surgical-pathological risk factors and outcome in clinical stage I and II carcinoma of the endometrium: a Gynecologic Oncology Group study. Gynecol Oncol 1991;40:55-65.

4. Brown AK, Madom L, Moore R, Granai CO, DiSilvestro P. The prognostic significance of lower uterine segment involvement in surgically staged endometrial cancer patients with negative nodes. Gynecol Oncol 2007;105:55-58.

5. Nag S, Erickson B, Parikh S, Gupta N, Varia M, Glasgow G. The American Brachytherapy Society recommendations for high-dose-rate brachytherapy for carcinoma of the endometrium. Int J Radiat Oncol Biol Phys 2000;48:779-790.

6. Kitchener H, Swart AM, Qian Q, Amos C, Parmar MK. Efficacy of systematic pelvic lymphadenectomy in endometrial cancer (MRC ASTEC trial): a randomised study. Lancet 2009;373:125-136.

7. ASTEC/EN.5 Study Group, Blake P, Swart AM, Orton J, et al. Adjuvant external beam radiotherapy in the treatment of endometrial cancer (MRC ASTEC and NCIC CTG EN.5 randomised trials): pooled trial results, systematic review, and meta-analysis. Lancet 2009;373:137-146.

8. Noumoff JS, Menzin A, Mikuta J, Lusk EJ, Morgan M, LiVolsi VA. The ability to evaluate prognostic variables on frozen section in hysterectomies performed for endometrial carcinoma. Gynecol Oncol 1991;42:202-208.

9. Alcázar JL, Galván R, Albela S, et al. Assessing myometrial infiltration by endometrial cancer: uterine virtual navigation with three-dimensional US. Radiology 2009;250:776-783.

10. DelMaschio A, Vanzulli A, Sironi S, et al. Estimating the depth of miometrial involvement by endometrial carcinoma: efficacy of transvaginal sonography vs MR imaging. AJR Am J Roentgenol 1993;160:533-538.

11. Antonsen SL, Jensen LN, Loft A, et al. MRI, PET/CT and ultrasound in the preoperative staging of endometrial cancer - a multicenter prospective comparative study. Gynecol Oncol 2013;128:300-308.

12. Ortoft G, Dueholm M, Mathiesen O, et al. Preoperative staging of endometrial cancer using TVS, MRI, and hysteroscopy. Acta Obstet Gynecol Scand 2013;92:536-545.

13. Rieck GC, Bulman J, Whitaker R, Leeson SC. A retrospective review of magnetic resonance imaging in assessing the extent of myometrial infiltration for patients with endometrial carcinoma. J Obstet Gynaecol.2005;25:765-768.

14. Jantarasaengaram S, Praditphol N, Tansathit T, Vipupinyo C, Vairojanavong K. Three-dimensional ultrasound with volume contrast imaging for preoperative assessment of myometrial invasion and cervical involvement in women with endometrial cancer. Ultrasound Obstet Gynecol 2014;43:569-574.

15. Preferred Reporting Items for Systematic Reviews and Meta-Analyses (PRISMA) website. Available at: http://www. prisma-statement.org/ 
16. Leeflang MMG, Scholten RJPM, Rutjes AWS, Reitsma JB, Bossuyt PMM. Use of methodological search filters to identify diagnostic accuracy studies can lead to the omission of relevant studies. J Clin Epidemiol 2006;59:234- 240.

17. Higgins JPT, Thompson SG, Deeks JJ, Altman DG. Measuring inconsistency in meta-analyses. BMJ 2003;327:557560.

18. Saarelainen SK, Kööbi L, Järvenpää R, Laurila M, Mäenpää JU. The preoperative assessment of deep miometrial invasion by three-dimensional ultrasound versus MRI in endometrial carcinoma. Acta Obstet Gynecol Scand 2012;91:983-990.

19. Alcazar JL, Pineda L, Martinez-Astorquiza Corral T, et al. Transvaginal/transrectal ultrasound for assessing myometrial invasion in endometrial cancer: a comparison of six different approaches. J Gynecol Oncol 2015;26:201-207.

20. Mascilini F, Testa AC, Van Holsbeke C, Ameye L, Timmerman D, Epstein E. Evaluating myometrial and cervical invasion in women with endometrial cancer: comparing subjective assessment with objective measurement techniques. Ultrasound Obstet Gynecol 2013;42:353-338.

21. Ergenoglu M, Akman L, Terek MC, et al. The prediction of myometrial infiltration by three-dimensional ultrasonography in patients with endometrial carcinoma: a validation study from Ege University Hospital. Med Ultrason 2016;18:201-206.

22. Rodríguez-Trujillo A, Martínez-Serrano MJ, MartínezRomán S, et al. Preoperative Assessment of Myometrial Invasion in Endometrial Cancer by 3D Ultrasound and Diffusion-Weighted Magnetic Resonance Imaging: A Comparative Study. Int J Gynecol Cancer 2016;26:1105-1110.

23. Green RW, Valentin L, Alcazar JL, et al. Endometrial cancer off-line staging using two-dimensional transvaginal ultrasound and three-dimensional volume contrast imaging: Intermethod agreement, interrater reliability and diagnostic accuracy. Gynecol Oncol 2018;150:438-445.

24. Christensen JW, Dueholm M, Hansen ES, Marinovskij E, Lundorf E, Ørtoft G. Assessment of myometrial invasion in endometrial cancer using three-dimensional ultrasound and magnetic resonance imaging. Acta Obstet Gynecol Scand 2016;95:55-64.

25. Yang T, Tian S, Li Y, et al. Magnetic Resonance Imaging (MRI) and Three-Dimensional Transvaginal Ultrasonography Scanning for Preoperative Assessment of High Risk in Women with Endometrial Cancer. Med Sci Monit 2019;25:2024-2031.

26. Yildirim N, Saatli B, Kose S, et al. Predictability of myometrial, lower uterine segment and cervical invasion with 3D transvaginal ultrasonography and magnetic resonance imaging in endometrial cancer patients: a prospective cohort study. Med Ultrason 2018;20:348-354.

27. American cancer society. Survival rates for endometrial cancer. Available from: https://www.cancer.org/cancer/ endometrial-cancer/detection-diagnosis-staging/survivalrates.html. Accessed November 2020.

28. Alcázar JL, Gastón B, Navarro B, Salas R, Aranda J, Guerriero $\mathrm{S}$. Transvaginal ultrasound versus magnetic resonance imaging for preoperative assessment of myometrial infiltration in patients with endometrial cancer: a systematic review and meta-analysis. J Gynecol Oncol 2017;28:e86.

29. Alcázar JL, Orozco R, Martinez-Astorquiza Corral T, et al. Transvaginal ultrasound for preoperative assessment of myometrial invasion in patients with endometrial cancer: a systematic review and meta-analysis. Ultrasound Obstet Gynecol 2015;46:405-413.

30. Andreano A, Rechichi G, Rebora P, Sironi S, Valsecchi MG, Galimberti S. MR diffusion imaging for preoperative staging of myometrial invasion in patients with endometrial cancer: a systematic review and meta-analysis. Eur Radiol 2014;24:1327- 1338 .

31. Luomaranta A, Leminen A, Loukovaara M. Magnetic resonance imaging in the assessment of high-risk features of endometrial carcinoma. A meta-analysis. Int J Gynecol Cancer 2015;25:837-842.

32. Das SK, Niu XK, Wang JL, et al. Usefulness of DWI in preoperative assessment myometrial invasion in patients with endometrial carcinoma: a systematic review and metaanalysis. Cancer Imaging 2014;14:32. 